Emotion as the Animation of Value

By: Frances Bottenberg

Bottenberg F. (2016) Emotion as the Animation of Value. In: Simmons J.A., Hackett J.E. (eds) Phenomenology for the Twenty-First Century. Palgrave Macmillan, London, pp. 141-156.

Made available courtesy of Springer Nature and Palgrave Macmillan:

https://doi.org/10.1057/978-1-137-55039-2 8

***(C) The Author. Reprinted with permission. No further reproduction is authorized without written permission from Springer Nature. This version of the document is not the version of record. Figures and/or pictures may be missing from this format of the document. $* * *$

\begin{abstract}
:
In this chapter, Frances Bottenberg argues that influential contemporary theories of emotion have yet to solve the classic puzzle of how the peculiar felt aspect of emotion is to be linked with its normative salience for particular action. This is in part due to how little mainstream attention has so far been paid to the role of the first-person body in emotional life. Building on recent and classic phenomenological insights, Bottenberg argues that emotional drive is best understood as an intelligent sensitivity played out not simply in but by the first-person body. In this so-called animationist reading of emotional valuing, emotional drive expresses the constant intracorporeal enactment of and adaptation to the fluctuating agent/world relationship.
\end{abstract}

Keywords: existential valuing | emotional experiences | emotional valuing | animationist Book Chapter:

$* * *$ Note: Full text of chapter below 


\title{
Emotion as the animation of value
}

\author{
Frances Bottenberg
}

\section{Beyond percepts, markers and signals}

Contemporary integrative theories of emotion aim to provide adequate accounts of the relationship between emotional feeling and evaluative meaning. Central among these are perceptualist accounts and what might be termed "signalist" accounts. Perceptualism in its weaker form demonstrates significant phenomenal and epistemic similarities between emotional and perceptual experience, and in its stronger form classifies emotion as a kind of perception, for instance as "a perception of value" (Nussbaum 2001, 1-2). ${ }^{1}$ The signalist viewpoint meanwhile promotes emotional life as a system of pre-established mechanisms waiting to be set off by appropriate eliciting conditions. Emotion thereby becomes representational, acting as a signal, sensor, marker, alarm or beacon to alert higher level consciousness to conditions imminently affecting the organism. ${ }^{2}$

Both perceptualism and signalism produce valuable insights. On the one hand, perceptualism encourages the exploration of phenomena that operate largely pre-reflectively and pre-linguistically, opening up realms once thought automatic and dumb to serious philosophical examination. Signalist theories, on the other hand, make sense of emotion's normative content within a coherent biological, physiological and neurological overview of the emotional system. In so doing, they revive William James' insight regarding the intimate bond between the somatic and the evaluative in emotion.

Despite these insights, however, contemporary approaches to emotion fall short of providing a satisfying account of the first person body's role in emotional life. In particular, perceptualist accounts do not solve the classic puzzle of emotion theory, namely how the felt aspect of emotion is to be linked with its normative salience for action. The puzzle remains as

\footnotetext{
${ }^{1}$ Among those theorists who endorse weaker versions of perceptualism are included Ronald de Sousa (1987), Louis Charland (1997), Sabine Döring (2007), Christine Tappolet (2000), Peter Goldie (2004, 2009), Bennett Helm (2001), Martha Nussbaum (2001), Deborah Achtenberg (2002), Robert Roberts (2003), Michael Stocker (2008) and Julien Deonna (2006). Döring and Tappolet, for instance, consider emotions to be instructively similar because both emotions and perceptions are non-inferentially and perspectivally structured and are, in their view, non-rational. For other theorists, including Deonna and de Sousa, emotions present "evaluative facts," which, like simply descriptive facts, track information about the agent-world relationship. While descriptive facts represent the world visually, tactilely, aurally, gustatorily, and olfactorily, evaluative facts reveal what we care about. Finally, some perceptualists, such as Goldie, Helm and Stocker, emphasize phenomenological affinities between emotion and perception, more precisely, the inseparability of their intentional, perspectival, and qualitative content. Jesse Prinz (2004, 2007) adopts a stronger form of perceptualism, reducing emotion to a kind of perception. For Prinz, emotions are perceptions of bodily changes, which in turn signal so-called core relational themes, which concern agent and world relationships (such as, for example, the threat of harm). Cf. Mikko Salmela (2011) provides an excellent survey and critique of perceptualism in contemporary emotion theory.

${ }^{2}$ The signalist assumption forms the basis of the emotion theories of Antonio Damasio and Jesse Prinz. Damasio's somatic marker hypothesis (1996; 1994/2006), founded in neurology and anti-Cartesian sentiment, remains the most widely known contemporary attempt to shed light on the essential interaction (or even unity) of physical and mental in the case of emotional experience. Philosopher Jesse Prinz' theory of embodied appraisal (which is a strongly perceptualist theory) builds on Damasio's ideas, adding an account of the intentionality of emotion. The smoke detector, or the tones emitted by the smoke detector, is Prinz's preferred analogy to capture the manner in which emotions signal matters of concern to reflective agency.
} 
daunting as ever, even granting that many similarities exist between perceptual and emotional experience. Further, while we remark upon the dynamic nature of emotional processing, theories still tend to fall back on a mechanistic and third-person picture of somatic life and emotional drive. The task thus remains to understand the nature of emotional drive in relation to endogenous movement and sense-making both at the reflective and pre-reflective levels.

In what follows, I will argue that emotional drive is best understood as an intelligent sensitivity that plays out within the first person body. ${ }^{3}$ In effect, my aim in this essay is to take up Maxine Sheets-Johnstone's challenge to place to the side the notion of the "embodied mind" and of "embodiment" as a general classification of human experience. Instead, the following inquiry takes seriously the concept of "mindful body" and a first person bodily "kinetic logos" (Sheets-Johnstone 1999, 487, 506). To do this, I will argue that the first person body is the primary locus of emotional agency and develop what could be called an animationist account of emotional valuing. This account considers emotional drive to be the result of an ongoing pre-reflective transcription of existential-evaluative meanings into the motor-kinetic dynamism of emotional experience. I believe that such an approach can rescue the pre-reflective and non-linguistic sphere of emotional events from the unyielding concepts of automaticity, simple reflex, and mechanism, and in this way offer some progress towards solving the classic puzzle of emotion theory.

\section{Emotional impulse and existential valuing}

I propose beginning with a concrete emotional experience. When we are really angry, so angry "our blood boils," do we feel more inclined to shout and gesticulate, or to lie down and close our eyes? Naturally, the former. Releasing outward-directed, explosive, loud force feels in the moment more fluidly and immediately available than slow, inward-retreating action. Of course, in deference to our moral principles, sense of decorum or simple caution, we may restrain ourselves to a greater or lesser degree from releasing that force. However, such restraint does not feel good or right in the heat of the moment.

One way to make sense of this situation is to consider every array of motor-program options (not just those involved in emotion) as constrained by normative parameters - to put it simply, the 'I can' being always subordinated to the 'I should' or 'I shouldn't' (where, it must be stressed, the 'I' needn't refer to self-conscious ego, but simply an active agency, or a concerted and directed sense of effort and concern). While my body can do many things, for effective action its capacities must be curtailed to suit the ends of a given context. Rosenbaum et al (1993) speak of "soft constraints," Ratcliffe of "pragmatic concern" and practical possibility:

The world is not configured solely in terms of what I can do with it. A sense of how I might act is tied up with a sense of what might happen, what might be avoided and what cannot be avoided. In addition, my possibilities are entangled with the possibilities that the world offers for others. I also sometimes experience an absence of the relevant practical possibilities, as a sense of loss that pervades everything. (Ratcliffe 2008, 127)

\footnotetext{
${ }^{3}$ The first person body is the Leib or "lived body" of classic phenomenological analysis. It denotes the subjective quality of embodied experience and stands conceptually opposite to the body as physical thing (Ding) interacting with other objects.
} 
In the case of acute anger, when and where is the vividness of one action-option (shouting, clenching one's fists) and the obscurity of the other (lying down, closing one's eyes) generated? In the motor programs themselves, or in some low level perception of these after they have already begun executing? Neither of these options seems quite right, because vividness and obscurity are phenomenal qualities known as such only in the process of experiencing, yet it is their particular effect that seems to usher us down one course of action rather than another. Leaving questions of causal priority aside for now, it is enough to grant the importance of the 'should do' in defining the 'can do' - phenomenologically speaking, it seems to found the feeling of immediate availability that comes along with the selection and selectivity of actions, especially in scenarios involving choice.

Two comments are in order concerning this last point. First of all, to those who might object to the priority I seem to be placing on the normative motivation of actions over the capacity to actually perform those actions, I should stress that I do not take the 'I should' to be independent of the 'I can.' Norms are shaped as much by capacities (i.e. the behavioral possibilities) as vice versa. For example, one's concept of power and ability to deploy that power "arise on the ground of the body one is" (Sheets-Johnstone 1999, 156). A healthy child relative to a healthy adult can muster less physical strength, yet may be more nimble - the child's sense of bodily capacity will hence be defined by his or her lived experiences of relative weakness and nimbleness, while the child's sense of motor possibilities will be delimited by his or her sense of capacity.

Secondly, to assuage doubts regarding the key role that normative constraint plays in the execution of actions, I ask you to imagine someone whose sensory-motor system is intact and who possesses an active sense of capacity, but who nonetheless lacks the sense of normative motivation which impels the performance of certain actions over others. The intuitive conclusion is that such a person would pass as being quite conscious, yet for all intents and purposes behave very much like the person in a persistent vegetative state. As a matter of fact, we needn't rely on intuitions here - such a case has been documented by Antonio Damasio, and his diagnosis and observations are quite consistent with the intuitive assessment just offered.

It is the very peculiar condition of suspended animation which brings our thought experiment to life. Damasio describes the case of a Mrs. T, who, for months after a stroke damaged the anterior cingulate cortex region of her brain, lies nearly motionless, blank-faced, and almost speechless in bed. She will occasionally pull her bed sheet up higher (assumed by Damasio to be a purely reflexive, autonomically-commanded action) or repeat her name, the names of loved ones or the name of her childhood town, but that is all. When she emerges from this mutism and akinesia a few months later, Mrs. $\mathrm{T}$ insists that she was indeed conscious, yet never felt herself to be imprisoned by her immobile and laconic state. As best she can report on the experience, she states that she simply felt no motivation to do anything other than she did: "I really had nothing to say" (Damasio 1996/2006, 73).

Worth noting here is that suspended animation is a case distinct from indecision, where the motivation to decide and act remains intact - indeed the frustration of feeling torn between alternatives is an essential trait of the latter condition. Living in suspended animation seems akin to simply not caring to choose, feeling no reason to choose, and as a result, not executing sophisticated and self-directed acts. Without the felt normative constraining and weighting of our possibilities for action, the very motivation for performing any voluntary act seems to diminish or even disappear. ${ }^{4}$

\footnotetext{
${ }^{4}$ The anterior cingulate cortex (ACC) is generally recognized as key in generating the effort needed to carry out any motivated action, including pre-reflective actions such as emotion. Research shows that it is in the ACC that emotion, attention, and working memory interact "so intimately that they constitute the source for the energy of both external action (movement) and internal action (thought animation, reasoning)" (Damasio 1996/2006, 71).
} 
If it is true that the motor-behavioral possibilities sensed while caught up in an emotion are arrayed in a preferential order, with some options feeling more vivid and viable, and others more obscure and unappealing, the question then becomes how these possibilities become harnessed to the attractive and aversive valences that are part and parcel of the experience of an acute emotion. Why are certain hedonic valences associated with certain emotions? To answer this it is inadequate to claim that emotional feelings parse out along a scale of pleasant, good feeling at one end and unpleasant, bad feeling at the other, and that these hedonic tones can be sourced back to the negative or positive meaning of the emotional target. This is the kind of view endorsed by Bennett Helm, for instance, when he states that "emotions are essentially feelings of things as good or bad in a certain way, and it is because these things feel good or bad to us that we can understand emotions to be pleasant or painful" (Helm 2009, 249). Jan Slaby (2008, 433) suggests this solution solves the "problem of emotionality from the outset." Since pleasures and pains are consciously felt states with hedonic character, they could convey "a very direct sense of the fact that it is indeed the goodness or badness of something that is apprehended in emotional experiences."

This accounting for the link between emotional feeling and hedonic tone is fundamentally perceptualist in nature. The felt "apprehending" of something as good or bad is cast as the chief process and end of emotional experience. The flaw in this conception is that it leaves entirely unexplained the link between emotional feeling and more or less vivid or obscure motor possibilities. Put bluntly, it does not address the very meaning of the word emotion, which comes from the Latin ex (out) and movere (move); as early as the twelfth century, emouvoir was used in Old French to mean 'to perturb' or 'agitate' (OED 2012). In light of this explanatory omission, I submit that a productive theorizing of emotional feelings requires examining emotional feelings' kinetic tone in relation to the corporeal circumstances at play in a given situation. It is relatively uncontroversial to state that emotions are first and foremost expressions of relational concerns that have to do with the agent's well-being and well-faring in the world. As Nussbaum puts it, emotions concern "the salience for our wellbeing of uncontrolled external objects" (2001, 1-2). Here I have in mind very basic existential-relational values such as threat, loss, gain, strengthening, weakening, community, autonomy, violation, vitality, viability, purposiveness, and efficacy.

How do emotional feelings relate to the sensing of and responding to existential values on an animationist account? My proposal is that kinetic tone, a fundamental quality of animation, performs or enacts existential-relational meanings in emotional experience. Some illustrations are in order. Consider emotions as varied as animosity, jealousy, or frustration. These are typically felt through a kinetic tone of aggression, which preferences quick, explosive actions. One has the feeling of bursting into and even through barriers. Defensive emotions afford deflective actions, and carry the sense of shrinking away and avoiding impact. Feelings of repose invite slower, relaxed actions, as does timidity, though it carries an additional sense of caution and self-diminishment. Outgoingness, joviality, even Wanderlust play out into open, expansive, even self-transcending forward impulsion. Where aggressive emotions seem to carry a sense of breaking through barriers, these happy emotions come with a sense of opening out into the environment, as if coming to embrace it or be assorbed into it.

The dorsal side of the ACC is neuronally linked both to the prefrontal cortex (the center of executive functioning, such as planning and decision-making) and the parietal cortex (where the somatosensory center of the human cortex, the postcentral gyrus, is located). As a result, the ACC is a central go-between for both 'topdown' and 'bottom-up' stimuli and controls. The ventral section of the ACC connects to the amygdala, the nucleus accumbens, the hypothalamus and the anterior insula, which constitute the much-studied processing centers for emotion and motivational information (cf. LeDoux 1998). As noted, research suggests the ACC is especially active when effort is required for action, including acts of learning and reasoning (cf. Allman et al 2001). 
Furthermore, which shades of emotion we assign to which kinetic tones or values need not be determined by whether one shade is always felt as unpleasant and another always as pleasant, because there just is no such invariant emotional tone; any shade of emotion can be felt as good or bad depending on the emotional target. Anger, for example, can feel liberating and self-enhancing when it is self-righteous, or discouraging and self-diminishing (or even self-destructive) when founded on recognized betrayal. The former case feels 'good,' the latter not so, yet both can receive the label 'anger.' Both correlate to a certain sense of capacity and normative motivation: a sense that, in the first case, I can and am entitled to act out this anger, and in the second case, that I can't undo or retaliate against the injury or insult already rendered.

A puzzle emerges. If the proprioceptive feelings involved in emotional experience are built on an established repertoire of kinetic tones that express existential significance, one wonders how it is that proprioceptive feelings switch from relating exclusively to things happening in and to the body to relating to the agent's better or worse faring in the world. To begin with, one might assume that all proprioceptive feelings are valenced a certain way from the start, i.e. that particular sensations are inherently assessed and felt as pleasant or painful. These pleasant and unpleasant sensations are then paired with anticipated events which are marked as good or bad, depending on past exposures. However, while it's true that some bodily sensations feel good or bad in and of themselves (for example, a muscle cramp or overextending a joint is always painful), these sensations do not map well onto emotional feelings. A stomach cramp feels awful and can appear in emotions such as dread or grief. However, not every experience of dread or grief comes with uncomfortable visceral tightness. There are also many sensations that are neither painful nor pleasant on their own (e.g. the feeling of a quickening heartbeat), and will be felt as unpleasant or pleasant only upon contextualization. This first solution hence requires a strict association between proprioceptive sensation, hedonic tone and event which seems absent in concrete reality.

An underexplored solution is to doubt that there is a switch at all: proprioceptive feelings are always already about the agent's faring in the world. The often tacit assumption that bodily feelings must either be intra-corporeally directed, i.e. be about bodily states, or extra-corporeally directed, i.e. be about things outside the body, deserves serious reexamination. Some scholars have indeed articulated an insight that calls this assumption into question: to focus attention on the agent or the world is to make a claim of emphasis, not one of difference. Matthew Ratcliffe (2008, 111), for example, writes that:

I might well be aware of my tiredness, my sickness or my fatigue as states of myself, but I might equally be aware of them as states of the world. The unengaging, distant world can be what solicits sleep when one is very tired; thirst may be most conspicuous as the perceptual salience of a running stream; and various perturbations in the way the world appears might partly constitute the experience of illness.

Further, as Max Scheler points out, "In the feeling of fatigue there is a warning that may be expressed in the language of common sense as 'stop working' or 'go to sleep... The vertigo we experience when we stand before an abyss urges us to 'step back'(1992, 82)." Ludwig Binswanger observes that, "When we are in a state of deeply felt hope or expectation and what we have hoped for proves illusory, then the world - in one stroke - becomes radically 'different.' We are completely uprooted, and we lose our footing in the world" (Binswanger 1968, 222).

Emotional feelings, just like non-emotional feelings (whose existence this thesis in fact puts into question), cannot do without this unifying perspectivalism. Feelings are always 
situated within the world as seen from the agent's perspective and are significant only in virtue of that perspective. Our feelings come out of the submersion of the extra-corporeal in the sphere of the intra-corporeal; as Ratcliffe $(2008,1)$ puts it: "World-experience is not distinct from how one's body feels; the two are utterly inextricable." But the opposite seems to occur just as often, that is, a submersion of the intra-corporeal in the sphere of the extracorporeal. "The Nausea isn't inside me," Sartre puts it graphically, "I can feel it over there on the wall, on the braces, everywhere around me. It is one with the café, it is I who am inside $i t^{\prime \prime}(1963,35)$.

Ratcliffe, Scheler, Sartre and Binswanger are all expressing the same insight, it seems: feelings, and especially emotional feelings, bring to the fore the dynamic, fluctuating relationship between the agent's exerted force on the world and the world's exerted force on the agent. Binswanger considers more closely the example of disappointment, wherein, he urges, we lose our footing in a manner felt viscerally and not simply metaphorically:

In such a moment our experience actually suffers, is torn from its position in the world and thrown upon its own resources. Until we can regain our equilibrium in the world, our whole existence moves within the meaning matrix of stumbling, sinking, and falling. If we call this general meaning matrix the 'form,' and the bitter disappointment the 'content,' we can see that in this case form and content are one. (ibid., 223)

What more can be said of the 'meaning matrices' of emotional feeling? One way to flesh out this notion is by returning to the issue of intentionality within emotional experience. When we are emotionally engaged in the world, we feel pulled towards certain objects or features of objects and away from others - we are affectively propelled. Donn Welton's analysis of affectivity within pre-reflective intentionality offers much to the account I am developing here. Rejecting the cognitivist idea that we are affectively drawn to objects because of a prior appraisal, Welton instead surmises that

our previous 'felt' involvement with [objects] establishes kinetic values giving them the enticing powers they have. What Husserl calls 'affective force' is in play. ... The body is not secondary to the affect, added either to account for its cause or its effect. Rather, the tendency to move in one way and not another is inherent in the being of the affect. (Welton 2008, 19)

Welton isolates three features which he posits as key in the organization of affective intentionality: (1) a feeling that, like Dewey's "pervasive quality," unifies the experience and gives it efficacy; (2) a motor tendency that lends the action animated by the feeling its direction; and (3) a valence to the object, its "soliciting feel." These three together produce the telos of the emotion, Welton writes, "whose kinetic values reflexively draw the action as a whole" (ibid., 13).

In the remainder of the essay, I will explore the idea that emotional feeling just is the transposition of the world's existential impingement on or enhancement of the agent into a register of kinetic enactments. These kinetic enactments of relational concerns, I submit, are the basis of a robust phenomenological conception of animation. In one sense, to speak of a singular value is misleading; we are dealing with modes of value - the kinetic-somatic and the existential-relational. Yet, in another sense, we must speak of value in the singular, since emotional feeling collapses these two distinctive modes into one, what might be called the kineto-existential mode of valuing. 
Jan Slaby proposes $(2008,437)$ that emotional feelings are a "bodily sensitivity for what is significant in the world." From its inception, the organism acts upon and is sensitive to the environment it is distinct from. It defines both itself and the world it takes in by boundaries imposed through experience; these boundaries are physical and chemical, somatic and social, and in sophisticated organisms also conceptual, metaphorical and (proto)linguistic. These boundaries are fluid and flexible, and thus require an intelligent sensitivity. Out of this intelligent sensitivity emerge the dynamics at play in emotional experience, what might be termed the dynamics of self-motivated somatic change, or selfaffectation. These dynamics somatically enact the fluctuating agent/world relationship, establishing Binswanger's meaning matrices in that interaction.

To say more precisely what this entails requires careful observation of the phenomenon of self-movement and the sensing of such movement. I wish to note three trailblazers in this venture. First, Maxine Sheets-Johnstone's work has much to offer, even though she is dealing more broadly with, as she says, "thinking in movement," and has almost nothing to say about emotional experience in particular. Sheets-Johnstone $(1999,56)$ begins her analysis by observing that "we perceive the qualia of our own movement; our bodily feelings of movement have a certain qualitative character." We feel our movement as swift or slow, constricted or open, tense or loose, smooth or jerky, expansive or contractive, and so on. These qualia are not mental, but "the product of animation" (ibid., 57). Sheets-Johnstone distills four primary vectors from the many qualitative possibilities of self-sensed movement: tensional, linear, amplitudinal, and projectional (cf. also Sheets-Johnstone 1966). The tensional vector expresses the degree of effort felt in performing a movement, while the projectional vector captures how energy and force are released (hesitantly or ballistically, for example). The amplitudinal vector has to do with the felt expansive or contractive dimension of a movement, also in terms of the larger space occupied. Finally, the linear vector captures the contour and path described by a movement. While amplitudinal and linear qualitative vectors chiefly describe the spatial aspects of movement, tensional and projectional ones describe its temporal aspects.

Sheets-Johnstone surmises that "complexity of affect may be tied to complexity of movement" (Sheets-Johnstone 1999, 84/fn 16), but unfortunately says nothing more on the matter. Nevertheless, it seems that her four primary qualities of movement map well onto the kinetic values of emotional animation.

A second trail-blazer, Daniel Stern's notion of vitality affects makes the connection between emotional, existential-relational and kinetic value explicit. Vitality affects, as Stern defines them, are "qualities [of experience] that do not fit into our existing lexicon or taxonomy of affects [but that] are better captured by dynamic, kinetic terms, such as 'surging,' 'fading away,' 'fleeting,' 'explosive,' 'crescendo,' 'decrescendo,' 'bursting,' drawn out,' and so on" (Stern 1985, 54). These qualities can be analyzed and classified using Sheets-Johnstone's primary vectors. Here it is also worth recalling Binswanger's comment on disappointment: he describes it as the sense of "our whole existence [moving] within the meaning matrix of stumbling, sinking, and falling" (Binswanger 1968, 223). It is instructive to consider all emotional feelings as built on the interplay of dynamic pulses.

To apply the qualities of sensed self-movement to emotional dynamics and meaning, it is important to consider the range of action and behavior afforded by the diverse emotions. A trail-blazer in this regard is Slaby $(2008,439)$, who isolates three categories of action occurring within and through emotion. These are helpful in demonstrating the close bond between motor tendency, behavioral possibility and the kinetic values animated in emotion. First, what Slaby calls "full-blown action tendencies," which urge the performance of a particular action (often an interaction), such as, for example, running from a bear or kissing someone. Second, there are "tendencies towards expressions of emotions," i.e. actions which 
express emotion, such as clapping one's hands in delight, shouting in anger, or crying in sadness. Third, there are what Slaby calls "impossible movement impulses," such as (to use his examples) "wanting to sink into the ground in shame; wanting to 'explode' in anger; wanting to 'embrace the world' in intensive joy or euphoria; wanting to literally 'melt' in affection."

Experiencing emotion as it unfolds is a matter not of sensing or perceiving, but of being animated to $d o$ something, even sometimes to do impossible things, like disappearing when we feel embarrassed. The urge to act out kinetic values is what unites these categories of emotion-driven action, or, more specifically, the emotion-driven response through action. And what is responded to in every instance are sensations, perceptions and images touching on how the agent is faring in the world, as construed from within his or her vantage point. These ideas all manifest themselves in Slaby's rich description of fear and joy:

In fear, for example, we feel as if pushed down by a threatening external force - a bodily tendency that is even more clearly perceivable in states of shock or sudden surprise. The bodily dynamics in these cases can be described as a kind of sudden narrowing; we feel as if the volume of our body is shrinking as effected by the working of an external force. An opposing tendency in the dynamics of intentional bodily feelings is a characteristic widening experience that we have in states of extreme joy, well-being or pride. A good example is the feeling of satisfaction after one's work is done: Here, we might feel a kind of inner widening, an extension of our body volume, which is felt as something thoroughly positive and lets us feel quite "at home" in our current surroundings. In cases like this, it is our grasp of our current positive situation that consists in part in this widening of the felt body. (Slaby 2008, 436)

Slaby's account calls for closer descriptive analysis. How does the experience of fear, for example, break down more precisely at the level of kineto-existential dynamics? An experience of fear begins with the interoceptively sensed narrowing of body volume, which comes in conjunction with the visualized (or otherwise externally sensed) object of threat. It is crucial to realize that both are needed to produce the current of kinetic energy that animates the agent toward particular behavioral possibilities. What determines how this engagement unfolds, though, is the interaction between the two modes of value at play in emotional experience, namely the kinetic and the existential-relational. In a typical case of fear, an object of threat is seen, but its impact is felt through the body volume shrinking. Put more strongly, the significance of the emotional object is fed into the first person body's projections of possibilities for action. The essence of feeling threatened lies in it seeming as if the threatening object has already begun to assault the agent; the assault is imagined as occurring, its presence already sensed as a real pressure or force bearing down upon and shaking up the perimeter that separates agent from world. From the perspective of the agent, this constitutes a violation of her autonomy and her desire for self-preservation. Against the felt narrowing and contracting of the body a counter-force thus arises, one that re-affirms and shields the existential values currently violated. Stern's choice of the term vitality to qualify affect dynamics is carefully chosen - fundamentally emotional experience arises in the face of challenges to (or enhancements of) the agent's sense of his or her own vitality and viability. In our present example, we can assume the object continues to appear as threatening. The kinetic value animated in fear is not, as it would be in anger, one that affords lashing out at the object to force it to withdraw. Instead, the kinetic value animated in the experience of fear affords hiding or withdrawal strategies (actions which remove the agent from the incursion of the threat-object). In withdrawing, the agent's sensed body volume 
increases and the felt acuteness of her fear - in other terms, the kinetic energy grounding her fear - dissipates.

\section{Moving forward with kineto-existential phenomenology}

Animation is a term rich with meaning. The term connotes, on the one hand, a sense of inspiration and encouragement, of liveliness of manner, vivacity, and the process by which something becomes lively or enlivened, and, on the other hand, a sense relating to life and action per se: "The action or process of imparting life, vitality, or (as a sign of life) motion; quickening, vitalizing" (OED 2011, I.1-3 and II.4.a). These meanings are metaphysically neutral, that is, they need not be linked with a dualist or Judeo-Christian notion of animation as 'ensoulment,' the imparting of life to otherwise lifeless matter through the soul (anima).

I have argued in this paper that the experience of emotion is made up of not only phenomenal and epistemological structures, but also performative ones, and that the transposition of existential value into the realm of the kinetic is at the heart of emotional agency and sense-making. It is for this reason that I call my approach animationist. In other words, animation, as I am using it, is meant to unite under one concept both the selfmovement and the self-motivation of living systems (the common Latin root is motus, lit. a motion). The 'self' involved in this may be quite primitive, something akin to the Gibsonian ecological self; the relevant distinction is between that which is animate and that which is inanimate. The inanimate is neither alive nor self-moving, and can be manipulated by external forces alone; it is determinate mechanism.

It is worth noting that I am not the first to draw on the phenomenologically fertile concept of animation. As central as the sense of self-capacity (what Husserl in Ideas II and III and later Merleau-Ponty label the 'I can') is to phenomenological accounts of the foundational structures of somatic experience, its early theorizers recognized that this sense in turn is dependent on even more basic capacities: that of self-movement and the sensing of self-movement. Husserl writes that "Animation designates the way in which mind acquires a locality in the spatial world, its spatialization, as it were, and together with its corporeal support, acquires reality" (Husserl 1977, 101). One is also reminded of Bergson's élan vital (vital impulse) and Schopenhauer's concept of the will-to-live. A number of recent theorists have recognized animation as necessary for knowledge. Sheets-Johnstone, for instance, following in the tradition of genetic phenomenology, calls somatic animation "the generative source of our primal sense of aliveness and of our primal capacity for sense-making" (1999, 132). Enactivists and situated mind theorists such as Francisco Varela, Evan Thompson, and Andy Clark, metabiologist Gerald Edelman and cyberneticist Humberto Maturana - among others - bind together organism-level sense-making and movement by describing forms of organic self-organization. This is the notion of autopoiesis.

It is my hope that the animationist approach I have begun to flesh out here can contribute to the investigation of what Sheets-Johnstone $(1999,142-143)$ calls the "cardinal structures of kinesthetic consciousness," where kinesthetic consciousness is the pre-reflective awareness of an "unfolding kinetic dynamic." This is a difficult project because it is a challenge to verbalize. As Sheets-Johnstone herself points out, "It is not only difficult to find adequate adjectives or nouns by which to describe the different qualities we experience in moving, but difficult to avoid unwanted associations along the way" (ibid., 148-9). How well do terms such as 'force,' 'effort,' and 'energy' capture dynamic tendencies, for example? The previous section's descriptions of 'the inside' of emotional dynamics end by creating an impression of static content, or at best a call-and-response interaction between agent, object and world. However, there can be nothing static or unidirectional about the animation that is 
at the heart of emotional experience; it is nothing else but the continuous generation of movement (im)pulses in the midst of ongoing adjustments between agent and world.

No doubt many questions remain regarding the motivational awareness at play in emotional experience and the two modes of value which I have suggested are collapsed therein. Do the animative qualities of emotional experience follow or do they generate the meanings I have been calling existential? What is the relation of the performance of these qualities to rational knowing and thinking? These are the central questions most deserving of further attention.

\section{BIBLIOGRAPHY}

Achtenberg, D. (2002) Emotions as perceptions of value. In: Cognition of value in Aristotle's ethics. Albany: SUNY Press, pp. 159-178.

Allman, J. M., Hakeem, A., Erwin, J. M., Nimchinsky, E., Hof, P. (2001) The anterior cingulate cortex. The evolution of an interface between emotion and cognition. Annals of the New York Academy of Sciences 935 (1): 107-17.

Binswanger, L. (1968) Being-in-the-world: Selected papers. New York: Harper \& Row.

Charland, L. C. (1997) Reconciling cognitive and perceptual theories of emotion: A representational proposal. Philosophy of Science 64: 555-579.

Cole, J. (1995) Pride and a daily marathon. Cambridge, MA: MIT.

Damasio, A. (1996) The somatic marker hypothesis and the possible functions of the prefrontal cortex. Philosophical Transactions: Biological Sciences 351 (1346):1413-1420.

Damasio, A. (1996/2006) Descartes' error: Emotion, reason and the human brain. London: Vintage.

De Sousa, R. (1987) The rationality of emotion. Cambridge: MIT Press.

Deonna, J. A. (2006) Emotion, perception, and perspective. dialectica 60: 29-46.

Döring, S. (2007) Seeing what we do: Affective perception and rational motivation. dialectica 61: 363-394.

Dunn, T. G., Gillig, S. E., Ponser, S. E., Weil, N. (1986) The learning process in biofeedback: Is it feedforward or feedback? Biofeedback \& Self-Regulation 11(2): 143-55.

Gallagher, S. (2006) How the Body Shapes the Mind. New York: Oxford University Press.

Ghez, C. (2000) The control of movement. In: Principles of neural science. Kandel, E., Schwartz, J., Jessell, T. (eds). New York: McGraw-Hill.

Goldie, P. (2004) Emotion, feeling, and knowledge of the world. In: Thinking about feeling, R. C. Solomon (ed). Oxford/New York: Oxford University Press, pp. 91-106. 
Goldie, P. (2009) Getting feelings into emotional experience in the right way, Emotion Review 3: 232-239.

Helm, B. W. (2009) Emotions as evaluative feelings. Emotion Review 1: 248-255.

Husserl, E. (1977) Ideas pertaining to a pure phenomenology and to a phenomenological philosophy. Second book: Studies in the phenomenology of constitution (Ideas II). R. Rojcewicz and A. Schuwer (eds/trans). Dordrecht: Springer.

LaCroix, J. M. (1981) The acquisition of autonomic control through biofeedback: The case against an afferent process and a two-process alternative. Psychophysiology 18: 573-87.

LeDoux, J. E. (1998) The emotional brain: the mysterious underpinnings of emotional life. New York: Simon \& Schuster.

Lephart, S. M., Riemann, B. L, and Fu, F. H. (2000) Introduction to the sensorimotor system. In: Proprioception and neuromuscular control in joint stability. Windsor, Ontario: Human Kinetics, pp. xvii-xxiv.

Nussbaum, M. (2001) Upheavals of thought. The intelligence of emotions. Cambridge/New York: Cambridge University Press.

OED. animation. 2012. In oed.com (Oxford English Dictionary Online). http://www.oed.com/view/Entry/61249?rskey=vbmnZS\&result=1\&isAdvanced=false\#eid (July 14, 2012).

OED. emotion. 2012. In oed.com (Oxford English Dictionary Online).

http://www.oed.com/view/Entry/61249?rskey=vbmnZS\&result=1\&isAdvanced=false\#eid (December 15, 2011).

Prinz, J. (2004) Gut reactions: A perceptual theory of emotion. New York: Oxford University Press.

Prinz, J. (2007) Is emotion a form of perception? In: The modularity of emotion, L. Faucher and C. Tappolet (eds). Canadian Journal of Philosophy supplementary vol. 32, pp. 137-160.

Ratcliffe, M. (2005) The feeling of being, Journal of Consciousness Studies 12: 43-60.

Ratcliffe, M. (2008) Feelings of Being: Phenomenology, Psychiatry and the Sense of Reality. London/New York: Oxford University Press.

Riemann, B. L., Lephart, S. M. (2002) The Sensorimotor System, Part I: The Physiologic Basis of Functional Joint Stability, Journal of Athletic Training 37 (1): 71-79.

Roberts, R. C. (2003) Emotions. Cambridge: Cambridge University Press.

Rosenbaum, D. A., Vaughan, J., Jorgensen, M. J., Barns, H. J., and Stewart, E. (1993) Plans for object manipulation. In: Attention and Performance XIV: Synergies in Experimental 
Psychology, Artificial Intelligence, and Cognitive Neuroscience, D. E. Meyer and S. Kornblum (eds). Cambridge, MA: MIT Press.

Sacks, O. (1985) The man who mistook his wife for a hat. London: Duck-worth.

Salmela, M. (2011) Can emotion be modelled on perception? dialectica 65 (1): 1-29.

Sartre, J. P. (1963) Nausea. R. Baldick (trans). London: Penguin.

Scheler, M. (1992) On Feeling, Knowing and Valuing: Selected Papers. Chicago/London: Chicago University Press.

Sheets-Johnstone, M. (1994) The roots of power: Animate form and gendered bodies. Peru, IL: Open Court.

Sheets-Johnstone, M. (1999) The primacy of movement. Amsterdam/Philadelphia: John Benjamins.

Simoneau, M., Paillard, J., Bard, C., Teasdale, N., Martin, O., Fleury, M., Lamarre, Y. (1999) Role of the feedforward command and reafferent information in the coordination of a passing prehension task. Experimental Brain Research 128: 236-242.

Slaby, J. (2008) Affective intentionality and the feeling body. Phenomenology and Cognitive Science 7: 429-444.

Stern, D. (1985) Interpersonal world of the infant: A view from psychoanalysis and developmental psychology. New York: Basic Books.

Stocker, M., and Hegeman, E. (1996) Valuing emotions. Cambridge, MA: Cambridge University Press.

Tappolet, C. (2000) Emotions et valeurs. Paris: Presses Universitaires de France.

Welton, D. (2008, October) The emergence of affectivity and action. Presented at the Society for Phenomenology and Existential Philosophy annual meeting, Pittsburgh, PA. 